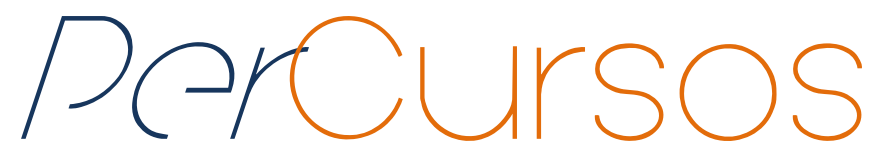

\title{
Colonialidade do poder e a violência contra os povos indígenas
}

\begin{abstract}
Resumo
Para compreender a violência contra os Povos Indígenas no Brasil contemporâneo, faz-se necessário partir de uma análise sistêmica e de longa duração, considerando que ela incide fundamentalmente sobre a territorialidade de povos, seja nas disputas por terra, seja no impedimento de manifestarem-se livremente a partir de seus pressupostos culturais. Uma das chaves para compreender essa questão é pensar a violência a partir da Colonialidade do Poder, conceito proposto pelo sociólogo peruano Aníbal Quijano, analisando que mesmo com as independências das colônias dos impérios ibéricos, o poder colonial se manteve. A violência se configura através do "epistemicídio", pela tentativa de eliminação das práticas e saberes indígenas. Na contemporaneidade, a violência é fundamentalmente institucional, seja na ação do Estado brasileiro reduzindo direitos como a não demarcação dos territórios e a implantação de obras desenvolvimentistas que afetam esses povos, seja na omissão, imiscuindose e permitindo assassinatos e invasão das terras indígenas.
\end{abstract}

Palavras-chave: Violência; Indígenas; Colonialidade.

\author{
Clovis Antonio Brighenti \\ Doutor em História pela \\ Universidade Federal de Santa \\ Catarina - UFSC. Professor de \\ História Indígena da Universidade \\ Federal da Integração Latino \\ Americana - UNILA / PR. \\ Brasil
}

clovis.brighenti@unila.edu.br

\section{Para citar este artigo:}

BRIGHENTI, Clovis Antonio. L Colonialidade do poder e a violência contra os povos indígenas. Revista PerCursos. Florianópolis, v. 16, n.32, p. 103 -120, set./dez. 2015. 


\title{
Coloniality of power and violence against indigenous peoples
}

\begin{abstract}
To understand the violence against indigenous populations in contemporary Brazil, it is necessary to perform a systemic and long term analysis, considering that it fundamentally affects the territoriality of the populations, whether in land disputes, or in the impediment of free manifestations based on their cultural assumptions. One of the keys for understanding is to think violence from the point of view of Coloniality of Power, concept proposed by the Peruvian sociologist Aníbal Quijano, who argues that even with the political independences from the imperialist Iberian colonies, the colonial power still remained. The violence is made in form of "epistemicide," by the attempt of elimination of indigenous knowledges and practices. Today, violence is essentially institutional, whether in the actions of the Brazilian State, reducing the rights of these groups, or not demarcating the territories and performing works for the development of the country, and also in the omission, interfering and allowing murders and invasion of indigenous lands.
\end{abstract}

Keywords: Violence; Indigenous people; Coloniality. 


\section{Introdução}

Para compreender a violência contemporânea contra os povos indígenas é necessário fazeruma análise sistêmica de longa duração. Sistêmica, porque não basta analisar dados estatísticos, é preciso compreender a subjetividade da violência, como ela é sentida, percebida e compreendida pelos próprios povos indígenas, a partir das suas cosmosvisões. Algumas ações que podem não parecer violência a um legislador ou administrador público, justificando como algo natural do exercício da administração pública ${ }^{1}$, pode carregar elementos que rompem com historicidades e com continuidades de práticas sociais.

A morosidade na demarcação de uma terra indígena ou mesmo a paralisação total do processo na esfera administrativa, em muitos casos tardando mais de duas décadas para acontecer, pode significar o rompimento de transmissão de conhecimentos entre gerações. Uma criança que se torna adulta debaixo de barraco de lonas em beira de estradas, ou mesmo em locais impróprios em fundos de fazenda, não terá a oportunidade de conviver com algumas práticas econhecimentos tradicionais, como atividades de cultivo e manejo de sementes tradicionais, fundamental para a manutenção e reprodução da cosmológica. ${ }^{2}$

Não é por acaso que o suicídio entre indígenas no Mato Grosso do Sul, um dos estados mais violentos a essas populações, ocorre principalmente entre a maioria adolescente e jovem (80\% dos suicídios ocorreram com pessoas na faixa etária de 13 a 30

\footnotetext{
${ }^{1}$ Em 2012, a cacique da Terra Indígena Morro dos Cavalos ouviu do Ministro da Justiça Dr. José Eduardo Cardozo, em audiência nas dependências do ministério, que a referida Terra Indígena não seria Homologada pela Presidente Dilma Rousseff porque "os astros estão confluindo contra". (Anotações pessoais do autor.) A TI Morro dos Cavalos está com o processo administrativo concluído desde abril de 2008 quando foi assinada a Portaria Declaratória. Não há óbice administrativo ou judicial que impeça a homologação, apenas a opção política do governo externada pelo Ministro como problemas astrológicos. Enquanto a demarcação não ocorre, a referida comunidade ocupa uma pequena faixa de terra entre a rodovia BR 101 e um morro íngreme, não permitindo produzir alimentos.

${ }^{2}$ Benito Oliveira, liderança religiosa Guarani, manifestou-se aos jovens dizendo que, para continuar sendo Guarani, mais importante que a língua era a manutenção dos conhecimentos e práticas de cultivo das sementes tradicionais. Ocorre que a prática de cultivo implica necessariamente possibilidade de acesso à terra e a manutenção e transmissão desses conhecimentos entre gerações. (BRIGHENTI; CHAMORRO, 2012, p.257).
} 
anos, sendo que $17 \%$ deles ocorreram na faixa etária de $10-14$ anos e $36 \%$ na faixa etária de 15 a 19 anos). Nos últimos 15 anos 707 indígenas se suicidaram somente naquele estado.

\begin{tabular}{|l|l|l|l|l|l|l|l|l|l|l|l|l|l|l|l|l|}
\hline Ano & 2000 & 2001 & 2002 & 2003 & 2004 & 2005 & 2006 & 2007 & 2008 & 2009 & 2010 & 2011 & 2012 & 2013 & 2014 & Total \\
\hline $\begin{array}{l}\text { N. } .^{\circ} \text { de } \\
\text { Suicídios }\end{array}$ & 44 & 40 & 38 & 53 & 42 & 50 & 40 & 40 & 59 & 42 & 40 & 45 & 53 & 73 & 48 & 707 \\
\hline
\end{tabular}

Tabela 1- Mato Grosso do Sul - Suicídio entre indígenas - 2000 a 2014

Fonte CIMI, 2015, p. 117.

À análise sistêmica da violência podemos agregar também o conceito de violência simbólica, desenvolvido pelo sociólogo francês Pierre Bourdieu, incluindo nela toda forma de coação que se apoia no reconhecimento de uma imposição determinada, seja esta econômica, social ou simbólica. A violência simbólica é a manifestação da legitimidade do discurso dominante. Para Bourdieu (1992), a violência simbólica "é o meio de exercício do poder simbólico". A violência simbólica está estampada em grande parte dos livros didáticos e no cotidiano da maioria dos veículos de comunicação, ao reproduzir discursos de cunho racista e ideologicamente preconceituoso, como classificando e definindo quem é e não é indígena a partir de elementos externos; através de afirmações de que os indígenas possuem muita terra ${ }^{3}$; que os indígenas não podem impedir o progresso da Nação; que os costumes indígenas precisam ser modificados para integrálos à sociedade de consumo; e tantas outras formas de manifestação de cunho racista e preconceituoso. Porém, a violência simbólica também resulta em violência física, porque ao depreciar o outro, este se torna vulnerável a ações de terceiros, que justificam suas práticas pelo poder exercido sobre a suposta inferioridade do outro.

\footnotetext{
${ }^{3}$ Informações totalmente deturpadas e tendenciosas como a estampada no jornal Diário Catarinense, do grupo RBS, justificando a tramitação da Proposta de Emenda à Constituição n..$^{\circ}$ 215: "Índios: 0,4\% da população, $0 \%$ de produção e $13 \%$ do território nacional. Santa Catarina é o sexto maior produtor de alimentos com apenas $1,3 \%$ do território nacional. Decisões equivocadas ou baseadas em laudos fraudulentos - segundo o próprio ministro José Eduardo Cardozo - criam conflitos entre índios e agricultores. As reservas indígenas ocupam hoje $13 \%$ da área total do Brasil. As terras agricultáveis, que respondem por 200 milhões de toneladas de grãos, ocupam $8 \%$ do território. A população indígena é de $0,4 \%$ dos brasileiros. Funai, Ongs patrocinadas por multinacionais, padres oportunistas e antropólogos suspeitos querem elevar para $25 \%$ do território nacional as reservas indígenas. Os dados foram denunciados em Brasília pelo deputado Valdir Colatto (PMDB)." Disponível em: http://wp.clicrbs.com.br/moacirpereira/2013/12/15/indios-04-da-populacao-o-de-producao-e-13-do-territorionacional/?topo $=67,2,18, \ldots 67 \#$ comments. Acesso em 16/12/2013 às 07 h43min.
} 
A violência sistêmica é resultado do processo histórico de inferiorização do outro, tratando-o como não sujeito portador de direitos a partir de classificações autoritárias, que em cada momento histórico se fazem representar pela sociedade dominante de forma diferenciada. Assim, no período colonial a inferiorização dos grupos indígenas ocorria pelo conceito da fé cristã, por serem pagãos ou hereges; no século XIX a inferiorização ocorria pelo conceito da ciência, já que os indígenas eram considerados pertencentes a sociedades fora da História; e, no tempo contemporâneo pela inexorabilidade do progresso, manifestada em todas as esferas da sociedade pela crença de que os indígenas não evoluíram e atrapalham o progresso. Talvez a mais expressiva forma de manifestação da violência simbólica seja o racismo, que, como bem frisou Bonin (2015, p.41):

O racismo contra os povos indígenas se expressa tanto por meio de ações de pessoas e grupos, quanto pela omissão do Estado frente às violências praticadas e às reivindicações destes povos para que seus direitos constitucionais sejam respeitados. A violência não decorre da inexistência de mecanismos legais, mas da falta de efetividade destes, agravada imensamente pela inoperância do governo no que tange às demarcações das terras indígenas.

Na formulação de Bonin podemos agregar o conceito de "racismo institucional", que de acordo com Werneck (apud Silva, 2014) “(...) opera de forma a induzir, manter e condicionar a organização e a ação do Estado, suas instituições e políticas públicas atuando também nas instituições privadas, produzindo e reproduzindo a hierarquia racial".

Para compreender a violência sistêmica com relação aos povos indígenas é necessário aplicar o conceito da História de Longa Duração, entendendo que a violência é histórica e contínua. Nesse caso poderíamos dizer genericamente que a violência começou em 1492 ou 1500, com a chegada dos primeiros europeus neste continente (pelo menos de que se tem registro). Dada a limitação física de nosso artigo, faremos um recorte temporal a partir da criação do Estado brasileiro no século XIX, que se materializou com o processo de independência em 1822. Esse recorte justifica-se porque grande parte da violência que abordaremos tem a ver com o papel desempenhado pelo 
Estado na condução da política indigenista e, por conseguinte, na definição da relação da sociedade brasileira com esses povos. Em grande medida os povos indígenas contemporâneos são herdeiros da violência imposta pelo Estado.

\section{Violência história do Estado}

Manuela Carneiro da Cunha (1992) observa que no contexto da elaboração da primeira Constituição do Brasil independente, outorgada em 1824, não foi possível incluir nenhuma referência aos povos indígenas, como desejava o Patriarca da Independência, José Bonifácio de Andrada e Silva, em virtude das pressões exercidas pela oligarquia agrária da época. As ideias de José Bonifácio sobre a civilização dos índios brasileiros, questionadas na contemporaneidade, eram para a época um reconhecimento de que os indígenas deveriam ser portadores de direitos, mesmo que a partir do princípio individual como pressupunha o pensamento liberal francês. Os oligarcas da época, precursores do mesmo pensamento dos atuais ruralistas, não admitiram incluir o tema indígena na Constituição porque não consideravam os indígenas humanos, não sendo, portanto, sujeitos de direitos.

A partir do século XIX os indígenas foram paulatinamente sendo menos requisitados como mão de obra, mas as terras que eles ocupavam despertou enorme interesse na oligarquia. Nesse cenário foi o Estado brasileiro que regulamentou ${ }^{4}$ as relações que se estabelecem reduzindo constante e paulatinamente as terras ocupadas pelos indígenas - primeiro transferindo populações de seus territórios para aldeamentos civis e, na sequência, reduzindo e extinguindo esses aldeamentos.

Duas figuras se destacam nesse processo de criação do novo imaginário sobre os indígenas. O primeiro e principal deles foi Francisco Adolfo de Varnhagen (1816-1878): de acordo com Reis (1999, p.32),Varnhagen (...)

foi um historiador oficial, um adulador dos poderosos e juiz severo das revoltas populares. A história, para ele, é feita pelos grandes homens, por

\footnotetext{
${ }^{4}$ Vide Lei 601/1850, conhecida com Lei de Terras.
} 
reis, guerreiros e governadores, bispos e não pelos homens incultos. Foi a Casa de Bragança que construiu o Brasil íntegro, uno e independente.

Foi ele que influenciou todo o pensamento da nova Nação, ao partir da concepção segundo a qual os indígenas não tinham história, apenas etnografia. Foi defensor vigoroso da eliminação dos indígenas, porque as terras por eles ocupadas estavam "sedentas de braços laboriosos".

Já no Brasil republicano outra figura se destacou por formular conceitos para justificar o extermínio dos povos indígenas. Trata-se de Hermann Friedrich Albrecht Von Ihering (1850-1930), médico, professor, ornitólogo teuto-brasileiro e um dos fundadores do Museu Paulista. Foi defensor do extermínio da população Kaingang do Oeste paulista e, por conseguinte, de todos os indígenas que, segundo sua opinião, seriam empecilho para a colonização.

Temos quase um século, desde a fundação do Estado brasileiro, em que pensadores influentes defendiam abertamente a eliminação da população indígena. Associadas à área da ciência, a literatura e as artes também tiveram sua participação na criação do pensamento racista sobre os povos indígenas, contrapondo o "bom selvagem" aos "temíveis botocudos canibais". Nas obras imortalizadas de José de Alencar, Gonçalves Dias e Victor Meirelles (para citar apenas uma representação de cada segmento), o indígena aparecia oscilando entre o bom e aliado Tupi (considerado extinto), referenciadona autorrepresentação do Brasil,ou seja, o indígena do passado, contrastando com os Tapuias dos sertões, que deveriam ser eliminados. Esse conjunto de pensadores e suas obras contribuíram para formar em nossa literatura, especialmente nos livros didáticos, o imaginário do indígena "bom" do passado e do indígena "selvagem e inútil à Nação".

No início do século $\mathrm{XX}$, as estimativas demográficas indicavam uma população indígena de aproximadamente 1,5 milhões de indivíduos, já em 1957 Darcy Ribeiro estima números entre "um mínimo de sessenta e oito mil e cem e um máximo de novena e nove mil e setecentos" (RIBEIRO, 1972, p.431). Diz ainda que ao longo deste século oitenta e sete grupos foram exterminados e quase todos eles sofreram fortes reduções 
demográficas "e profundas transformações em seus modos de vida” (idem). Porém, há

uma singularidade no século $X X$ se comparado com o século anterior, qual seja, a participação ativa do Estado brasileiro como ator principal da violência. Diferentemente do século anterior, no XX há um conjunto de Leis que de certo modo eram mais vastas, mais presentes com maior alcance e teoricamente mais fáceis de serem fiscalizadas devido à sua maior difusão e proximidade dos tribunais. Para se ter uma noção de como era a aplicação das leis no período colonial, temos os registros de John Monteiro, ao citar um caso envolvendo os Caicaizes e Juruna da Ilha do Marajó, que foram tomados em “Guerra Justa”. Quando as respostas às denúncias levadas ao Conselho Ultramarino (criado em 1642 em Lisboa) chegavam de volta, cinco anos após a denúncia, o fato já estava consumado e os indígenas estavam todos vendidos (MONTEIRO, 1994).

Outro fator que agravava a violência praticada pelo Estado no século XX era o regime tutelar aplicado aos índios pela força do Código Civil de 1916. Cabia ao Estado a tutela e este fez uso para manter os indígenas cerceados do direito, transformando-os em “infantis", sem direitos, e as aldeias em "cerco da paz", como bem analisou Antonio Carlos de Souza Lima (1995).

Os indígenas estavam à mercê dos "chefes de postos", que pelo regime tutelar tinham poderes legais, e a depender do humor e dos interesses que estabeleciam com os regionais eram mais ou menos rígidos em aplicar sansões punitivas aos indígenas e liberar madeiras, terras e outros produtos para os empresários locais (BRIGHENTI, 2012b).

Resumidamente, os indígenas no século XX foram objeto dediferentes ações do Estado em quatro grandes momentos: O primeiro deles caracterizado pelo início da República como um grande vácuo de ações indigenistas. Desde a proclamação da República até 1906 a política indigenista brasileira ficou subordinada às Unidades da Federação (Decreto n. ${ }^{\circ}$ 07, de 20 de novembro de 1889, § 12: Promover a organização da estatística do Estado, a catequese e civilização dos indígenas e o estabelecimento de colônias). Pela força desse Decreto alguns estados criaram reservas indígenas, reduzindo os territórios dos antigos aldeamentos ou criando reservas, minúsculas, sobre os territórios tradicionais. Com a criação do Ministério dos Negócios da Agricultura, Indústria e Comércio (Decreto n. ${ }^{\circ} 1.606$, de 29 de dezembro de 1906. Art. $2^{\circ}$ ) o ministério passou a 
desempenhar as seguintes atribuições: b) immigração e colonização, catechese e civilização dos indios). Nesse cenário a política indigenista volta à jurisdição federal.

O segundo momento ficou caracterizado pela criação do Serviço de Proteção aos Índios (SPI) através do Decreto n. ${ }^{\circ}$ 8.072, de 20 de junho de 1910 (até 1918 era designado como Serviço de Proteção aos Índios e Localização dos Trabalhadores Nacionais), quando o Estado centraliza a ação indigenista na esfera federal e organiza toda uma burocracia para atuar com os povos indígenas. Esse segundo momento termina em 1967 com a extinção deste órgão e criação da Fundação Nacional do Índio (Funai) através da Lei n. ${ }^{\circ}$ 5371 de 05 de dezembro daquele ano. Foram 57 anos de atuação do SPI com grandes percalços e minado de contradições. Passou por vários ministérios e ao menos 26 presidentes. Às vésperas de sua extinção sofreu duas Comissões Parlamentares de Inquérito (CPIs) no Congresso Nacional e um Inquérito Federal (Portaria n. 239 de 1967)relativo à atuação de todo o órgão, além de inquéritos localizados por repartições ou regionalizados.

No início dos anos 1960, as denúncias de violações de direitos indígenas ganhavam manchetes nos principais jornais da Europa. O governo militar brasileiro não tinha como negar e tratou de atribuir a culpa aos adversários. Em 1967, o Ministro do Interior Albuquerque Lima criou um inquérito (Portaria n. 239 de 1967) para apurar as irregularidades do Serviço de Proteção aos Índios (SPI).OMinistro nomeou o Procurador Federal Jader Figueiredo Correa para proceder a um inquérito e apurar as irregularidades.

Jader Figueiredo percorreu o Brasil e produziu um relatório de 4.942páginas, conhecido como "Relatório Figueiredo", identificando crimes cometidos contra os indígenas pelos funcionários do SPI, os quais foram tipificadas da seguinte maneira:

Crimes a pessoa e a propriedade do índio; Assassinatos de índios (individualmente e coletivos: tribos); Prostituição de Índias; Sevícias; Trabalho escravo; Usurpação do trabalho do índio; Apropriação e desvio de recursos oriundos do patrimônio Indígena - Dilapidação do patrimônio Indígena; Venda de gado; Arrendamento de terras; Venda de madeira; Exploração de minérios; Venda de castanhas e outros produtos de atividade extrativa e de colheita; Venda de produtos de artesanato indígena; Doação criminosa de terras; Venda de veículos - Alcance de 
importâncias incalculáveis; Adulteração de documentos oficiais; Fraude em processo de comprovação de contas; Desvios de verbas orçamentárias; Aplicação irregular de dinheiros públicos; Omissões dolosas; Admissões fraudulentas de funcionários; Incúria administrativa. (FIGUEIREDO, 1968, p.06).

Os crimes praticados impressionaram o Procurador:

É espantoso que existe na estrutura administrativa do País repartição [SPI] que haja descido a tão baixos padrões de decência. E que haja funcionários públicos, cuja bestialidade tenha atingido tais requintes de perversidade. Venderam-se crianças indefesas para servir aos intentos de indivíduos desumanos. Tortura conta crianças e adultos, em monstruosos e lentos suplícios, a título de ministrar justiça. (FIGUEIREDO, 1968, p.02).

Durante os trabalhos da comissão foram assinalados 134 casos de inquéritos abertos contra funcionários além de 200 demissões, anulação de medidas administrativas, ameaças de mortes etc. Entre os indiciados estavam ex-ministros, dois generais, um tenente coronel e dois majores ex-diretores do SPI. Porém, o relatório foi arquivado sem efetivar as medidas apontadas pelo inquérito. Desaparece em 1968 e ressurge somente em 2012.

$\mathrm{Na}$ estrutura administrativa do SPI os chefes de postos indígenas (agentes do Estado responsável pela proteção e tutela) se concediam a prerrogativa de acusar, julgar e punir. Os "crimes", quase todos banais, tinham um viés bastante claro, impedir que os indígenas se rebelassem contra a exploração de suas terras pelo Estado. O castigo mais comum era o tronco:

Os espancamentos, independentes de idade ou sexo, participam de rotina e só chamava a atenção quando, aplicados de modo exagerado, ocasionava, a invalidez ou a morte. (...) O "tronco" era, todavia, o mais encontradiço de toso só castigo, imperando na $7^{\mathrm{a}}$ Inspetoria [a $7^{\mathrm{a}}$ Inspetoria localizava-se em Curitiba (PR), responsável por todos os Postos Indígenas no Sul do Brasil]. Consistia na trituração do tornozelo da vítima, colocado entre duas estacas enterradas junto a um ângulo agudo. As extremidades, ligadas por roldanas, eram aproximadas lenta e continuamente. (FIGUEIREDO, 1968, p.03). 
A partir dos fatos apurados por Jader Figueiredo, o Congresso Nacional criou uma nova CPI. Os deputados percorrem o Brasil para investigarin loco o que estava acontecendo. Ficaram estarrecidos com as violências praticadas contra os indígenas. Porém, devido ao fechamento do Congresso Nacional pelo Ato Institucional n. ${ }^{\circ} 5$, no dia 13 de dezembro de 1968, a CPI não conclui os trabalhos, porém produziu importante acervo de informações sobre a ação do Estado.

Além de explorar os recursos naturais, o Estado vendeu as terras indígenas ou barganhou com empresários locais como TI Xapecó, mais de 30\% entregue a empresários; TI Ibirama Laklãnõ, mais de 70\% roubadas; e outras entregues totalmente a empresários, como TI Toldo Imbu, Araçaí, Morro dos Cavalos, Pesqueiro etc. (todas em SC) (BRIGHENTI, 2012a).

Com a extinção do SPI e a criação da Funai em 1967, ocorreram mudanças profundas na atuação do Estado com os Povos Indígenas, especialmente no que tange à modificação da estrutura administrativa para dar conta de atender a política dos governos militares. Sua atuação foi dinamizada como a exploração dos recursos naturais e das produções agrícolas e pecuárias nas terras indígenas, através de seu Departamento Geral do Patrimônio Indígena (DGPI), criado para aprimorar a exploração das Terras Indígenas e transformar a Fundação numa empresa rentável e repressora.

Esse olhar, mesmo que rápido, para os séculos XIX e XX, nos ajuda a entender os conflitos contemporâneos. Sem compreender o significado dos territórios para os povos indígenas e as violências a que foram submetidos, não conseguiremos perceber a violência no presente, num momento crucial para a História Indígena brasileira, quando o movimento indígena vem sendo protagonista em seus atos, agora sem a tutela. Essa análise sistêmica e de longa duração nos faz compreender que a reconciliação com a história não é possível pelo esquecimento.

O Relatório da Comissão Nacional da Verdade, apresentado em 10 de dezembro de 2014, sintetiza dados de violência contra os povos indígenas cometidos no período de 1946 a 1988. (Disponível em: http://www.cnv.gov.br/. Acesso em: 10/12/2014). 


\section{Violência no tempo presente}

A violência no tempo presente surge associada às questões territoriais pela conquista e manutenção dos territórios. Nesse sentido ela não se manifesta de igual maneira em todo o país, mas concentra-se em regiões com maior incidência de jogos de interesse do capital. A esse aspecto chamamos de geografia da violência porque ela está distribuída geograficamente conforme determinações econômicas e históricas em áreas consideradas "pioneiras" ou novas zonas onde o capitalismo penetra com maior intensidade. Nas regiões consideradas consolidadas, manifesta-se através da intensificação da exploração. O capitalismo é extremamente intolerante, na medida em que avança a violência aumenta.

No início do século XIX foi o rompimento das "muralhas dos sertões" com o avanço da colonização sobre as terras Kaingang e Xokleng no sul do Brasil. Foi o período que esses povos perderam a maior parte de seus territórios. No governo de Vargas há um avanço sobre o centro oeste do Brasil e as intensificações da exploração das riquezas existentes nas poucas terras que restavam aos povos do Sul. Já nos governos militares, sem abandonar a exploração do que restava nas terras Kaingang e Xokleng, a violência se alastra pela Amazônia: rodovias como a Belém-Brasília e a Transamazônica, que dizimou dezenas de povos, a BR 174 (Manaus-Boa Vista, a Perimetral Norte), associada à hidrelétrica de Balbina, que em seu contexto gerou mais de 2,5 mil mortes do povo Waimiri-Atroari ${ }^{5}$, além das hidrelétricas de Tucuruí e Itaipu Binacional, esta última destruiu de vez grande parte do território Guarani entre Brasil e Paraguai.

No momento presente, dois cenários de violência se manifestam com maior intensidade. Um deles é onde o agronegócio encontra maior amparo institucional para manter-se e outro onde os interesses do Estado se fazem mais presentes, como a ocupação da região amazônica para a construção de hidrelétricas. Portanto, a geografia

\footnotetext{
5 "Os grupos Waimiri-Atroari foram massacrados, entre os anos 1960 e 1980, para abrir espaço em suas terras para a abertura da BR-174, a construção da hidroelétrica de Balbina e a atuação de mineradoras e garimpeiros interessados em explorar as jazidas que existiam em seu território. Recenseados pela Funai em 1972 com uma população de cerca de 3 mil pessoas, em 1987 eram somente 420, tendo chegado a 350 em 1983. (...)A Usina Hidrelétrica de Balbina inundou cerca de 30 mil hectares do território Waimiri-Atroari, e implicando na remoção de pelo menos duas aldeias." (BRASIL. COMISSÃO NACIONAL DA VERDADE, 2014, p. 234 e 235).
} 
da violência segue um padrão definido, qual seja, o lugar em que o capital avança com maior intensidade sobre os territórios indígenas.

A manutenção da violência não ocorre sem o amparo jurídico, que a legitima. Como os povos indígenas conquistaram direitos na Constituição Federal de 1988, no momento presente há centenas de iniciativa nas três esferas do poder que visam reduzilos. No poder executivo se manifesta através da paralisação da demarcação das terras, no sucateamento do órgão indigenista federal (Funai) e nas diversas Portarias restritivas de direitos, como a de número 303. No legislativo são diversas iniciativas na Câmara e Senado, como Projetos de Leis, Projetos de Decreto Legislativo, Projetos de Emendas Constitucionais (especialmente o de $n .{ }^{\circ} 215$ ) que incidem fundamentalmente no direito a terra (redução e impedimento da demarcação) e no uso das terras para mineração e exploração dos recursos naturais, ao dar guarida aos interesses do agronegócio, definindo que, se os indígenas não estavam na posse das terras em 5 de outubro de 1988, data da promulgação da CF, não têm direito a ela, transformando radicalmente o conceito de posse. Mesmo comunidades expulsas das terras pelo próprio Estado, arrancadas e transferidas à força sem poderem ajuizar ações por conta da tutela, não são consideradas portadoras de direitos pelo judiciário. Consideramos que é uma volta atrás nos direitos estabelecidos, um dos maiores retrocessos legais desde o Brasil Colônia, quando foi instituído o direito originário, através do instituto do indigenato, que essa é umadas principais violências que está em curso na história deste país.

Portanto, a violência é institucional, praticada pelo Estado pela ação e omissão. A omissão revela-se ao não cumprir as determinações legais. Dom Erwin Kräutler (2015) observa que "a omissão do poder público na condução da política indigenista é o descaso para com a vida destes povos." Afirma que "em 2013 a omissão se tornou ainda mais enfática quando o governo federal deixou de cumprir sua responsabilidade constitucional de realizar os procedimentos administrativos de demarcação" - de acordo com o Cimi (2015), de 2011 a 2015 o governo federal homologou apenas 16 terras indígenas, o menor índice desde 1985, quando o Brasil retomou os governos civis com José Sarney permitindo que se criem milícias armadas contra os povos indígenas, que resultam em centenas de assassinatos. De 2003 a 2013 ocorreram 754 assassinatos de indígenas no 
Brasil, dos quais 390 apenas no Mato Grosso do Sul (CIMI, 2015, p.76). Quando o Estado se omite impera a lei do mais forte, o que detém mais armas e dinheiro para contratar “segurança privada” e pagar campanhas eleitorais.

A ação do Estado revela-se na mudança dos marcos legais a fim de dar guarida ao grande capital e na concretização das obras consideradas de "desenvolvimento" que incidem diretamente sobre esses povos, como nos casos das hidrelétricas de Belo Monte, dos complexos dos rios Tapajós e Madeira e mais uma centena de obras que afetam esses povos. (BRIGHENTI, 2015). Dom Erwin Kräutler afirma que o

descaso do governo para com os direitos territoriais indígenas gerou também novas investidas contra esses povos, protagonizadas por grupos privados ou representantes públicos. Os dados coletados em 2013 evidenciam a promoção, por particulares, de inúmeros eventos públicos com o intuito de criminalizar as lutas indígenas e, ao mesmo tempo, desqualificar seus modos de vida. Também tem sido frequente a difusão de discursos com teor preconceituoso, discriminatório e racista em meios digitais de informação, bem como em jornais, programas de televisão e de rádio. $O$ "Leilão da Resistência", promovido por organizações ligadas à Confederação da Agricultura e Pecuária do Brasil (CNA) no Mato Grosso do Sul em 7 de dezembro, foi um desses eventos. (KRÄUTLER, 2015, p.11).

\section{Considerações finais}

A partir do entendimento acima formulado, a violência contra os povos indígenas tem sua origem no processo de colonização e se perpetua até a contemporaneidade. Esse continuum histórico está relacionado com aquilo que o sociólogo peruano Aníbal Quijano (2009) chama de colonialidade do poder.

Esse sociólogo, a partir de seus estudos sobre o pensamento descolonial, elaborou o conceito de colonialidade do poder, que nos ajuda a compreender como o projeto de colonização/dominação, iniciado no século XVI pelos países europeus, se perpetua até os dias atuais, tendo como principal executor e mantenedor dessa colonialidade o poder estatal. Para tanto, ele faz uma distinção entre colonialismo e colonialidade.

O colonialismo refere-se à situação de dominação política, econômica e territorial de uma determinada nação sobre outra de diferente território, a exemplo da colonização 
do Brasil por Portugal, das várias colônias espanholas na América Latina, das colônias inglesas na África etc., superadas pela independência política. Enquanto isso, a colonialidade do poder

é um dos elementos constitutivos e específicos de um padrão mundial de poder capitalista. Se funda na imposição de uma classificação racial/étnica da população do mundo como pedra angular daquele padrão de poder, e opera em cada um dos planos, âmbitos e dimensões, materiais e subjetivas, da existência cotidiana e da escala social. (QUIJANO, 2009, p. 73).

Essa conceituação explica porque mesmo depois de haver a independência política, a colonialidade continuou a ocorrer. Essa colonialidade se manifesta de diversas maneiras, porque opera a partir de estratégias através da dominação epistêmica. A imposição do conhecimento ocidental como o único e válido e a negação e destruição dos saberes dos povos originários se constituiu em um dos mais poderosos mecanismos de dominação. Não permitir o acesso a terra, é uma das estratégias de impedir que as práticas de vida tradicional possam continuar, eliminando assim todas as formas de saberes e conhecimentos diferentes dos da sociedade ocidental. Para Habermas (2004, p. 172)

a discriminação não pode ser abolida pela independência nacional, mas apenas por meio de uma inclusão que tenha suficiente sensibilidade para a origem cultural das diferenças individuais e culturais específicas (...) os cidadãos, mesmo quando observados como personalidades jurídicas, não são indivíduos abstratos, amputados de suas relações de origem.

Isso significa que, para os povos indígenas, a independência do Brasil não representou mudança na sua posição em relação ao Estado, porque para eles o reconhecimento da sua cidadania passa pelo reconhecimento da sua coletividade enquanto povo (nação), e a partir dessas coletividades assegurar a aplicação dos direitos sociais, econômicos e culturais.

Ao chegarem ao século XXI sem ter os direitos assegurados na prática, os povos originários intensificam suas ações pela garantia dos direitos, porque sabem quão 
avassaladora e violenta é a "modernidade" na relação da alteridade. No mundo globalizado, o outro, o diferente, tem espaço apenas como manifestação folclórica e não como possibilidade de viver a partir de sua cosmologia e cosmografia. A violência, nesse contexto, é a tentativa de impedir que vivam suas próprias práticas. Dentro do pensamento ideológico ocidental moderno, seja os de direita, seja os de esquerda, os pressupostos relativos aos povos indígenas se assemelham.

Os povos indígenas sabem que a conquista de seus territórios é a possibilidade de romper com a colonialidade do poder. Porém, é nesse campo que a violência se manifesta com mais veemência, porque é justamente o espaço em que a sociedade não indígena, especialmente os detentores do poder, mais resistem.

\section{Referências}

BONIN, lara. Racismo: desejo de exterminar os povos e omissão em fazer valer seus direiros. In: CIMI. Relatório: Violência contra os povos indígenas no Brasil. Dados 2014. Brasília: Cimi, 2015.

BOURDIEU, Pierre. O Poder Simbólico. Rio de Janeiro: Bertrand Brasil, 1992.

BRASIL. COMISSÃO NACIONAL DA VERDADE. Relatório: textos temáticos/ Comissão Nacional da Verdade. V. 2. Brasília: CNV, 2014.

BRIGHENTI, Clovis A. As terras indígenas em Santa Catarina. In: NÖTZOLD, A.L.V.; ROSA, H. A.; BRINGMANN, S. F. Etnohistória, História Indígena e Educação: Contribuições ao debate. Porto Alegre: Palotti, 2012a.

BRIGHENTI, Clovis A. O movimento indígena no oeste catarinense e sua relação com a Igreja Católica na Diocese de Chapecó nas décadas de 1970 e 1980. 2012, 564f. Tese. (Doutorado em História) - Universidade Federal de Santa Catarina, Programa de PósGraduação em História, Florianópolis: 2012b.

BRIGHENTI, Clovis A. O “desenvolvimento” versus os povos indígenas. In: CIMI. Relatório: Violência contra os povos indígenas no Brasil. Dados 2014. Brasília: Cimi, 2015.

BRIGHENTI, C.A.; CHAMORRO, G. Territorialidade e educação escolar indígena: Desafios da experiência Guarani em Santa Catarina. In: LANGER, P.P.; CHAMORRO, G. Missões, militância indigenista e protagonismo indígena. São Bernardo do Campo: Nunaduti, 2012. 
CONSELHO INDIGENISTA MISSIONÁRIO. Relatório: Violência contra os povos indígenas no Brasil. Dados 2014. Brasília: Cimi, 2015.

CUNHA, Manuela C. da. Política Indigenista no século XIX. In: (org.). História dos

Índios no Brasil. São Paulo: Cia da Letra e Secretaria. Municipal da cultura, Fapespe, 1992.

FIGUEIREDO CORREA, Jader. Relatório Figueiredo relativo a Portaria nº 239 de 1967. Brasília: Mim. 1968.

HABERMAS, J. A Inclusão do Outro. São Paulo: Loyola.2004.

KRAUTLER, Erwin. “Aquele que usou de misericórdia...Vaie faze tu o mesmo!” In: CIMI. Relatório: Violência contra os povos indígenas no Brasil. Dados 2014. Brasília: Cimi, 2015.

LIMA, A. C. S..Um Grande Cerco da Paz. Poder Tutelar, indianidade e formação do Estado no Brasil. Petrópolis: Vozes,1995.

MONTEIRO, John. O escravo índio, esse desconhecido. In: GRUPIONI. L. D. B. (org.). Índios no Brasil. Brasília: MEC, 1994.

MOTA, Lúcio T. O Instituto Histórico e Geográfico Brasileiro e as propostas de integração das comunidades no estado nacional. Diálogos, Maringá, v.2, p.149-175, 1998.

QUIJANO, Aníbal. Colonialidade do Poder e Classificação Social. In: SANTOS, Boaventura de Sousa, MENESES, Maria de Paula (Orgs.). Epistemologias do Sul. Coimbra: Edições Almedina. SA, 2009.

REIS, J. C. As Identidades do Brasil: de Varnhagen a FHC. Rio de Janeiro: FGV, 1999.

RIBEIRO, Darcy. Os índios e a civilização. Rio de Janeiro: Civilização Brasileira, 1970.

SILVA, Edson. Os povos indígenas e o ensino: possibilidades, desafios e impasses a partir da Lei 11.645/2008. In: SEMINÁRIO EDUCAÇÃO, RELAÇÕES RACIAIS E MULTICULTURALISMO: COMUNIDADES TRADICIONAIS E POLÍTICAS PÚBLICAS-SEREM, V, Florianópolis, 15 a 18/05/2014. Anais... Florianópolis: UDESC, 2014. 
Recebido em: 28/10/2015 Aprovado em: 27/01/2016

Universidade do Estado de Santa Catarina - UDESC

Centro de Ciências Humanas e da Educação - FAED

Revista PerCursos

Volume 16 - Número 32 - Ano 2015 revistapercursos@gmail.com 